\title{
Structural Changes in Nickel Silicide Thin Films under the Presence of $\mathrm{Al}$ and $\mathrm{Ga}$
}

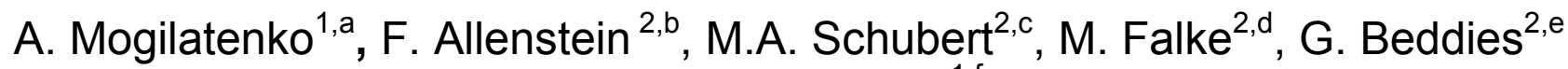 \\ and W. Neumann ${ }^{1, f}$ \\ ${ }^{1}$ Humboldt University of Berlin, Institute of Physics, Newtonstr. 15, 12489 Berlin, Germany \\ ${ }^{2}$ Chemnitz University of Technology, Institute of Physics, 09107 Chemnitz, Germany \\ ${ }^{3}$ Bruker AXS Microanalysis GmbH, Schwarzschildstrasse 12, 12489 Berlin, Germany \\ aanmog@physik.hu-berlin.de, brank.allenstein@physik.tu-chemnitz.de, \\ candreas.schubert@s2000.tu-chemnitz.de, 'Meiken.Falke@bruker-axs.de, \\ ebeddies@physik.tu-chemnitz.de, fwolfgang.neumann@physik.hu-berlin.de
}

Keywords: silicides, Nickel silicide, Aluminium, Gallium, thin films

\begin{abstract}
Thin $\mathrm{Ni} / \mathrm{Al}$ and $\mathrm{Ni} / \mathrm{Ga}$ layers of different atomic ratios were codeposited onto $\mathrm{Si}(001)$ at room temperature followed by subsequent annealing. Influence of annealing temperature on morphology and composition of ternary disilicide $\mathrm{NiSi}_{2-\mathrm{x}} \mathrm{Al}_{\mathrm{x}}$ and $\mathrm{NiSi}_{2-\mathrm{x}} \mathrm{Ga}_{\mathrm{x}}$ layers was investigated by transmission electron microscopy. Addition of $\mathrm{Al}$ or $\mathrm{Ga}$ leads to a decrease of the disilicide formation temperature from $700^{\circ} \mathrm{C}$ down to at least $500^{\circ} \mathrm{C}$. Depending on the composition closed, uniformly oriented $\mathrm{NiSi}_{2-\mathrm{x}} \mathrm{Al}_{\mathrm{x}}$ and $\mathrm{NiSi}_{2-\mathrm{x}} \mathrm{Ga}_{\mathrm{x}}$ layers were observed after annealing at $900^{\circ} \mathrm{C}$, whereas reaction of a pure $\mathrm{Ni}$ film with $\mathrm{Si}$ leads to the island formation with a mixture of $\mathrm{A}-$ and $\mathrm{B}-$ type orientations.
\end{abstract}

\section{Introduction}

In the recent decades strong interest has been drawn to the class of materials known as silicides [1], which are chemical compounds of silicon with different metals. Among them metallic silicides are of major importance for microelectronic devices. Their electrical properties as well as their excellent compatibility with Si have made them attractive for the use as ohmic contacts, Schottky barrier contacts, local interconnects and gate electrodes.

Formation of nickel silicide thin films on $\mathrm{Si}(001)$ has been intensively investigated, since the low resistant monosilicide phase $\mathrm{NiSi}$ is an attractive candidate as a contact material in Si-based ultralarge scale integration [2]. On the other hand the disilicide $\mathrm{NiSi}_{2}$ phase is interesting due to its cubic structure $\left(\mathrm{CaF}_{2}\right.$ structure type), which allows the growth of epitaxial layers on Si substrates [3]. Among all transition metal silicides $\mathrm{NiSi}_{2}$ shows the smallest lattice mismatch of $-0.4 \%$ to $\mathrm{Si}$. Despite the similarity of the crystal structures and the extremely low lattice mismatch the growth of closed uniformly oriented $\mathrm{NiSi}_{2}$ layers on $\mathrm{Si}(001)$ is a difficult task.

The first problem arising during the $\mathrm{NiSi}_{2}$ formation is fabrication of closed silicide layers. $\mathrm{Ni}$ atoms are the dominant diffusion species in $\mathrm{NiSi}_{2}$ formation [4]. Additionally, $\mathrm{Ni}$ bulk diffusion in $\mathrm{Si}$ strongly dominates its surface diffusion [5]. The high diffusivity of $\mathrm{Ni}$ atoms in Si prevents the formation of closed $\mathrm{NiSi}_{2}$ layers and leads to the island formation at high substrate temperatures [6]. The second problem is the formation of uniformly oriented layers. Generally, $\mathrm{NiSi}_{2}$ grows simultaneously in two orientations on Si, which are known as A-type and B-type orientations [7]. A-type orientation is formed when $\mathrm{NiSi}_{2}$ crystal structure has the same orientation as the $\mathrm{Si}$ substrate. The B-type orientation (also called twin orientation) represents A-type crystallites mirrored on one of the $\operatorname{Si}\{111\}$ planes. 
The third problem occurs during the $\mathrm{NiSi}_{2}$ growth on technologically relevant $\mathrm{Si}(001)$ substrates. Commonly, $\mathrm{NiSi}_{2}$ layers with planar atomically smooth interfaces are formed on $\mathrm{Si}(111)$ [8], whereas the epitaxial growth on $\mathrm{Si}(001)$ is accompanied by favorable formation of $\mathrm{NiSi}_{2}\{111\} / \mathrm{Si}\{111\}$ interfaces, which results in formation of pyramidal islands $[8,9]$.

It is possible to influence structural and physical properties of thin films by adding a substituting element, i.e. obtaining a ternary silicide. A number of authors analyzed thermal stability of nickel monosilicide phase, NiSi, during a solid state reaction of a number of metal/Ni bilayers on $\mathrm{Si}$ [1013]. Authors showed that an addition of such metals (Me) as $\mathrm{Pt}, \mathrm{Pd}, \mathrm{Ti}$, $\mathrm{Ta}$ or $\mathrm{W}$ to the Ni/Si thin film system results in formation of a monosilicide solution $\mathrm{Ni}_{1-\mathrm{x}} \mathrm{Me}_{\mathrm{x}} \mathrm{Si}$, which increases the monosilicide stability at high temperatures. In contrast, an addition of Co to the Ni-Si system results in formation of a disilicide solid solution $\mathrm{Ni}_{1-\mathrm{x}} \mathrm{Co}_{\mathrm{x}} \mathrm{Si}_{2}$ and leads to a decrease of the disilicide formation temperature [14-15].

Richter et al. analyzed for the first time the change of $\mathrm{NiSi}_{2}$ lattice parameters due to a substitution of Si by $\mathrm{Al}$ or $\mathrm{Ga}$ [16]. The zero lattice match to silicon is reached for the compositions of $\mathrm{NiSi}_{1.74} \mathrm{Al}_{0.26}$ and $\mathrm{NiSi}_{1.83} \mathrm{Ga}_{0.17}$ at room temperature. This reveals the possibility to fabricate nearly defect-free unstrained epitaxial layers, which is challenging for both technological and fundamental research.

Up to now there are only a few studies on the growth of Ni-Al-Si films [17, 18]. We reported for the first time on the structure of thin $\mathrm{NiSi}_{2-\mathrm{x}} \mathrm{Al}_{\mathrm{x}}$ and $\mathrm{NiSi}_{2-\mathrm{x}} \mathrm{Ga}_{\mathrm{x}}$ layers on $\mathrm{Si}(001)[19,20]$. In this study we summarize the observed results and discuss the formation of silicide phases, their structure and chemical composition in Ni-Al-Si and Ni-Ga-Si thin film systems. The influence of two parameters is considered: annealing temperature and content of substitution element ( $\mathrm{Al}$ or $\mathrm{Ga})$.

\section{Experimental}

Thin films of different atomic $\mathrm{Ni} / \mathrm{Al}$ ratios were codeposited onto $\mathrm{Si}(001)$ substrates by magnetron sputtering, whereas thin $\mathrm{Ni} / \mathrm{Ga}$ layers were codeposited by molecular beam epitaxy. In both growth processes $\mathrm{Ni}$ and the substitution element (Al or Ga) were deposited simultaneously at room temperature. The amount of the deposited Ni corresponds to a Ni layer thickness of about $20 \mathrm{~nm}$. The amount of deposited Al (resp. Ga) is described by the atomic ratio Ni/Al (resp. $\mathrm{Ni} / \mathrm{Ga})=1 / \mathrm{z}$. A detailed description of the growth procedures for $\mathrm{Ni} / \mathrm{Al}$ and $\mathrm{Ni} / \mathrm{Ga}$ samples is given in [19] and [20], respectively.

After deposition the $\mathrm{Ni} / \mathrm{Al}$ as well as $\mathrm{Ni} / \mathrm{Ga}$ samples were isochronically annealed in a $\mathrm{N}_{2}$ ambient for $30 \mathrm{~s}$ using rapid thermal annealing. The annealing temperature was varied from $450^{\circ} \mathrm{C}$ to $900^{\circ} \mathrm{C}$ in steps of 50 degrees. For comparison the same deposition procedures were carried out using a pure Ni film on $\mathrm{Si}(001)$.

The layer structure was characterized by transmission electron microscopy (TEM) in plan-view (Si[001]) as well as in cross-section (Si[110]) using a Philips CM20 microscope operating at $200 \mathrm{kV}$. Scanning transmission electron microscopy (STEM) and electron energy dispersive X-ray spectroscopy (EDXS) were carried out on a JEOL JEM2200FS microscope operating at $200 \mathrm{kV}$ and equipped with a Bruker XFlash 5030 EDS detector.

\section{Results}

Phase formation in Ni-Si system. Cross-sectional TEM imaging and electron diffraction revealed changes in the microstructure of pure $\mathrm{Ni}$ layers on $\mathrm{Si}(001)$ after annealing at different temperatures (Fig. 1). Closed polycrystalline monosilicide NiSi layers are formed after annealing at $500^{\circ} \mathrm{C}$ (Fig. 1a). An annealing at $700^{\circ} \mathrm{C}$ results in formation of silicide islands. Plan-view electron diffraction analysis shows the simultaneous presence of two silicide phases: polycrystalline NiSi and epitaxial $\mathrm{NiSi}_{2}$ (Fig. 1b). A complete transformation into the disilicide phase, $\mathrm{NiSi}_{2}$, is accomplished after an annealing at $800^{\circ} \mathrm{C}$. Samples annealed above $800^{\circ} \mathrm{C}$ consist of $\mathrm{NiSi}_{2}$ islands having a shape of 

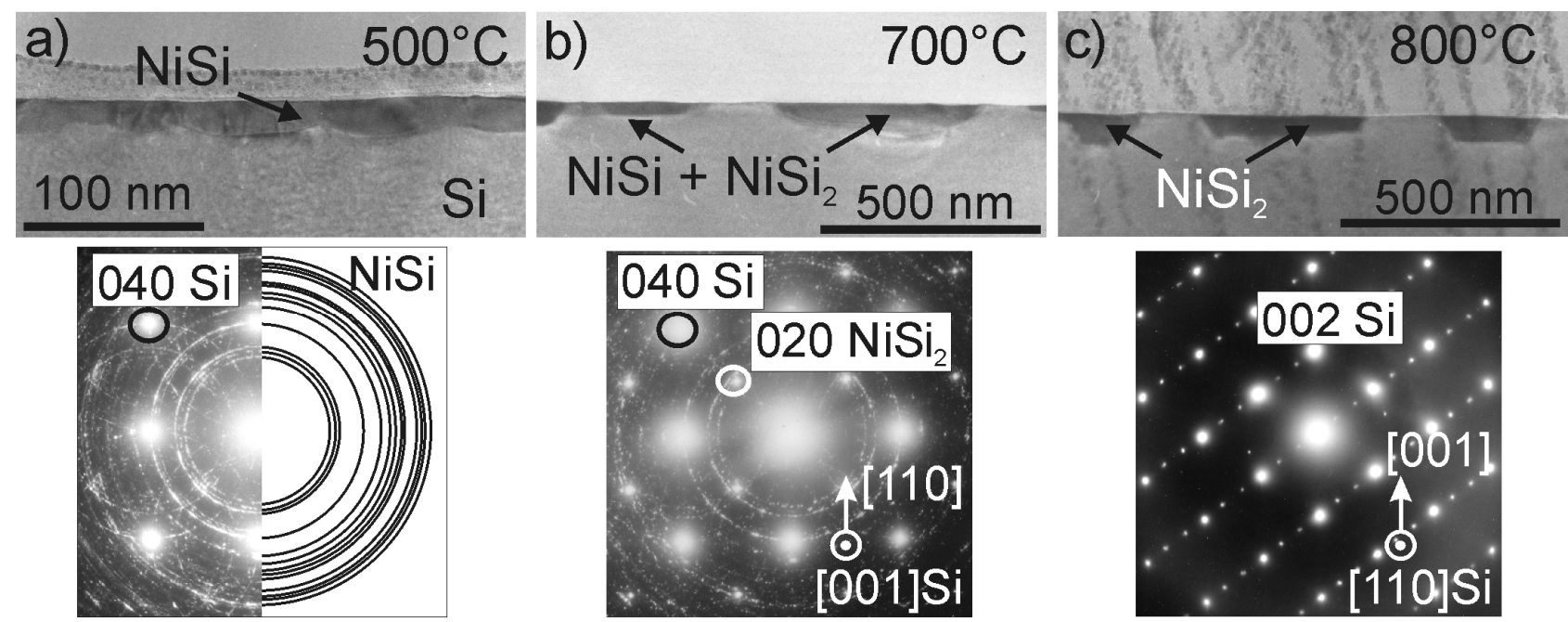

Figure 1: TEM cross-section images and corresponding electron diffraction patterns of Ni deposited onto $\mathrm{Si}(001)$ and subsequently annealed at a) $500^{\circ} \mathrm{C}$, b) $700^{\circ} \mathrm{C}$ and c) $900^{\circ} \mathrm{C}$. Notice that diffraction patterns in a) and $\mathrm{b}$ ) were obtained at plan-view specimens, i.e. in the $\mathrm{Si}[001]$ zone axis, whereas the diffraction pattern in c) - in the $\mathrm{Si}[110]$ cross-section. The white arrows in c) mark diffraction spots appearing due to the presence of B-type twins.

truncated pyramids (Fig. 1c). Electron diffraction analysis in Si[110] cross-section proved the presence of both A- and B-type orientations. These results are in full agreement with literature.

Phase formation in Ni-Al-Si system. An addition of Al into the Ni-Si system leads to a drastic change in the layer structure. The $\mathrm{NiSi}_{2}$ formation temperature decreases down to $500^{\circ} \mathrm{C}$. Isolated $\mathrm{NiSi}_{2}$ crystallites of about $10 \mathrm{~nm}$ in size were observed after a $500^{\circ} \mathrm{C}$ annealing at the $\mathrm{NiSi} / \mathrm{Si}$ interface already at an Al content $\mathrm{z}$ of 0.06 (Fig. 2a). They have a pyramidal shape and exhibit the A-type orientation. AES analysis (not presented here) showed that Al is concentrated only in the upper oxidized layer. An increase of Al content up to $\mathrm{z}=0.2$ leads to formation of a closed about $50 \mathrm{~nm}$ thick $\mathrm{NiSi}_{2-\mathrm{x}} \mathrm{Al}_{\mathrm{x}}$ layer with a rough $\mathrm{NiSi}_{2-\mathrm{x}} \mathrm{Al}_{\mathrm{x}} / \mathrm{Si}$ interface (interfacial roughness of about $30 \mathrm{~nm}$ ). This rough layer appears at the interface between a $20 \mathrm{~nm}$ thick polycrystalline $\mathrm{NiSi}_{0.5} \mathrm{Al}_{0.5}$ film and Si (Fig. 2b). The presence of the polycrystalline $\mathrm{NiSi}_{0.5} \mathrm{Al}_{0.5}$ film was proved by electron diffraction analysis elsewhere [19]. The similar sample structure was observed for Al contents ranging from $\mathrm{z}=0.2$ to $\mathrm{z}=0.35$. A further increase of the $\mathrm{Al}$ concentration up to $\mathrm{z}=0.6$ results in formation of a $40 \mathrm{~nm}$ thick NiAl layer with a closed $\mathrm{NiSi}_{2-\mathrm{x}} \mathrm{Al}_{\mathrm{x}}$ layer underneath (Fig. 2c). The $\mathrm{NiSi}_{2-\mathrm{x}} \mathrm{Al}_{\mathrm{x}}$ layer thickness decreases down to $30 \mathrm{~nm}$. Its interfacial roughness reaches about $40 \mathrm{~nm}$. The presence of NiAl phase was proved by electron diffraction. According to AES analysis there is an amount of Si solved in the upper NiAl layer. All the samples have an amorphous top layer Al-O.

Figure 3 shows cross-sectional images of $\mathrm{NiSi}_{2-\mathrm{x}} \mathrm{Al}_{\mathrm{x}}$ layers with different $\mathrm{Al}$ contents annealed at $900^{\circ} \mathrm{C}$. An annealing of pure $\mathrm{Ni}$ results in formation of large pyramidal $\mathrm{NiSi}_{2}$ islands separated by silicide-free substrate regions. It is visible that addition of $\mathrm{Al}$ leads to formation of closed $\mathrm{NiSi}_{2-\mathrm{x}} \mathrm{Al}_{\mathrm{x}}$ layers. The layer roughness strongly depends on the $\mathrm{Al}$ content. An addition of small amount of $\mathrm{Al}$ $(\mathrm{z}=0.06)$ leads to formation of a $\mathrm{NiSi}_{2-\mathrm{x}} \mathrm{Al}_{\mathrm{x}}$ layer with an interfacial roughness reaching up to 80 $\mathrm{nm}$. An increase of the $\mathrm{Al}$ content up to $\mathrm{z}=0.2 \ldots 0.3$ results in a drastic decrease of the layer roughness down to the nanometer scale. A further increase of the $\mathrm{Al}$ content up to $\mathrm{z}=0.6$ leads to a deterioration of the interface roughness up to $30 \mathrm{~nm}$.

According to electron diffraction analysis all $\mathrm{NiSi}_{2-\mathrm{x}} \mathrm{Al}_{\mathrm{x}}$ layers have the A-type orientation. No Btype oriented crystallites were observed in $\mathrm{NiSi}_{2-\mathrm{x}} \mathrm{Al}_{\mathrm{x}}$ layers, whereas pure $\mathrm{NiSi}_{2}$ layers deposited at the same growth conditions consist of a mixture of both orientations (Fig. 1c). 

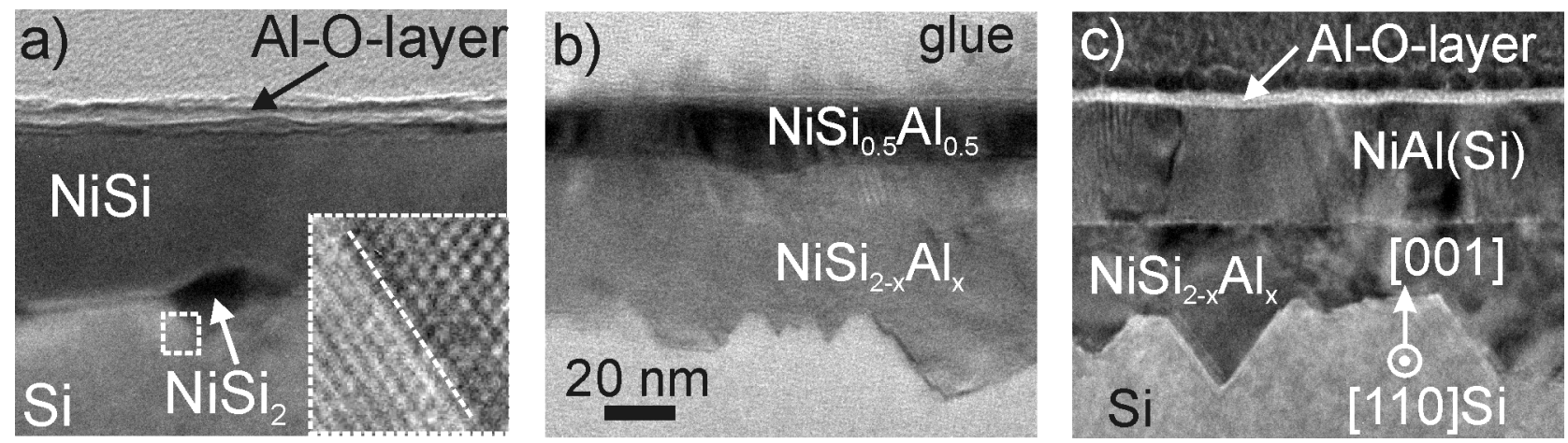

Figure 2: TEM cross-section images of $\mathrm{Ni} / \mathrm{Al}$ layers codeposited onto $\mathrm{Si}(001)$ using different $\mathrm{Ni} / \mathrm{Al}=1 / \mathrm{z}$ ratios a) $\mathrm{z}=0.06, \mathrm{~b}) \mathrm{z}=0.2$ and c) $\mathrm{z}=0.6$ after annealing at $500^{\circ} \mathrm{C}$. The inset in a) shows a high-resolution image of an A-type oriented $\mathrm{NiSi}_{2}$ grain with a $\mathrm{NiSi}_{2}\left(\begin{array}{ll}1 & 1\end{array}\right) / \mathrm{Si}(1 \overline{1} 1)$ interface.
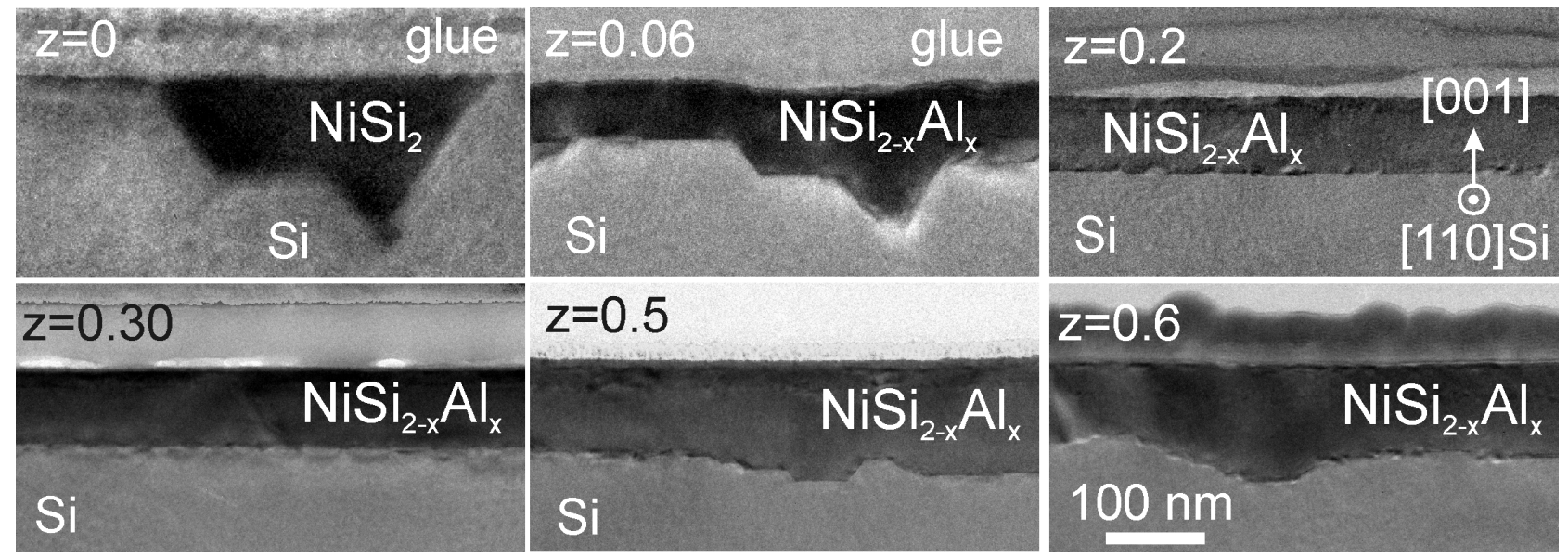

Figure 3: TEM cross-section images of Ni/Al layers codeposited onto $\mathrm{Si}(001)$ using different $\mathrm{Ni} / \mathrm{Al}=1 / \mathrm{z}$ ratios and subsequently annealed at $900^{\circ} \mathrm{C}$.

Phase formation in Ni-Ga-Si system. Similarly to the Ni-Al-Si thin film system an addition of Ga leads to a decrease of the disilicide formation temperature. At a $\mathrm{Ga}$ content of $\mathrm{z}=0.06 \ldots 0.17 \mathrm{a}$ mixture of $\mathrm{NiSi}$ and $\mathrm{NiSi}_{2-\mathrm{x}} \mathrm{Ga}_{\mathrm{x}}$ with a pure Ga layer on top was observed after annealing at $500^{\circ} \mathrm{C}$ [20]. Both phases grow polycrystalline.

For a higher Ga content $\mathrm{z}=0.22 \ldots 0.28$ epitaxial A-type oriented disilicide grains were observed already after annealing at $450^{\circ} \mathrm{C}$. In cross-section they can be recognized by their pyramidal shape (Fig. 4a). It is visible, that the sample consists of a number of layers. Plan-view electron diffraction analysis suggested a possible simultaneous presence of different structures with different compositions. It showed the presence of polycrystalline as well as epitaxial disilicide, textured monosilicide NiSi as well as epitaxial GaNi. Furthermore, formation of a number of different Ga-Ni as well as Ga-Ni-Si compounds is also possible. EDXS analysis was carried out to analyze the layer composition. Figure $4 \mathrm{~b}$ shows a STEM image of a pyramidal crystallite with the X-ray mappings of $\mathrm{Ga}, \mathrm{Ni}$ and Si peak intensities. According to this analysis the upper layer contains $\mathrm{Ga}$, Ni and $\mathrm{Si}$. However, the composition of the layer is not uniform. There is the highest Ga content in the $10 \mathrm{~nm}$ thick top-layer, whereas a $20 \mathrm{~nm}$ thick layer underneath shows a lower Ga content. The pyramidal disilicide grains are formed at the interface to $\mathrm{Si}$. Within the EDXS detection limit no Ga was observed in these pyramidal crystallites. This proves the simultaneous presence of the pure epitaxial $\mathrm{NiSi}_{2}$ phase.

After annealing at higher substrate temperatures there is a change in the layer structure. Without $\mathrm{Ga}$ isolated $\mathrm{NiSi}_{2}$ crystallites (A- as well as B-type oriented) grow above $800^{\circ} \mathrm{C}$ predominantly with the $\mathrm{NiSi}_{2}\{111\} / \mathrm{Si}\{111\}$ interfaces (Fig. 1c). For $\mathrm{z}$ ranging from 0.06 to 0.17 closed $\mathrm{NiSi}_{2-\mathrm{x}} \mathrm{Ga}_{\mathrm{x}}$ layers with a corrugated interface were observed in the temperature interval from $600^{\circ} \mathrm{C}$ to $750^{\circ} \mathrm{C}$ (Fig. 5a). The silicide grains do not grow epitaxially. Electron diffraction analysis showed that they 
exhibit a $\mathrm{NiSi}_{2-\mathrm{x}} \mathrm{Ga}_{\mathrm{x}}(110) \| \mathrm{Si}(001)$ texture. These closed layers break up in the samples annealed at $900^{\circ} \mathrm{C}$, which results in the island formation (Fig. 5a). The islands maintain the (110)-texture.
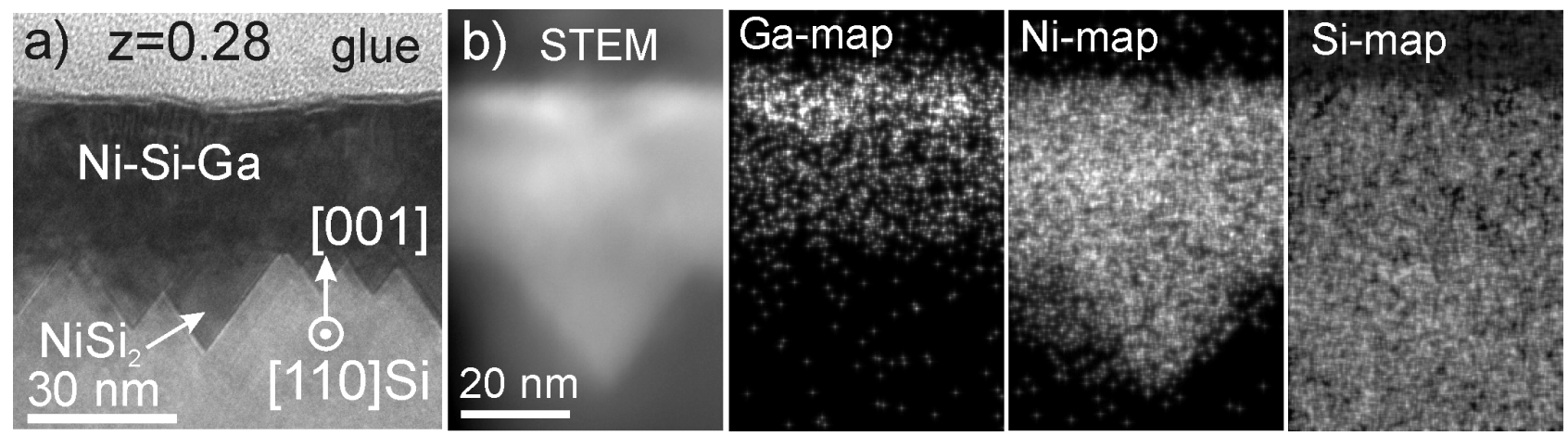

Figure 4: a) Cross-sectional TEM image of the sample structure with a Ga content $\mathrm{z}=0.28$ after annealing at $450^{\circ} \mathrm{C}$. b) STEM image of a pyramidal crystallite with the EDXS mapping of Ga, Ni and Si peak intensities.
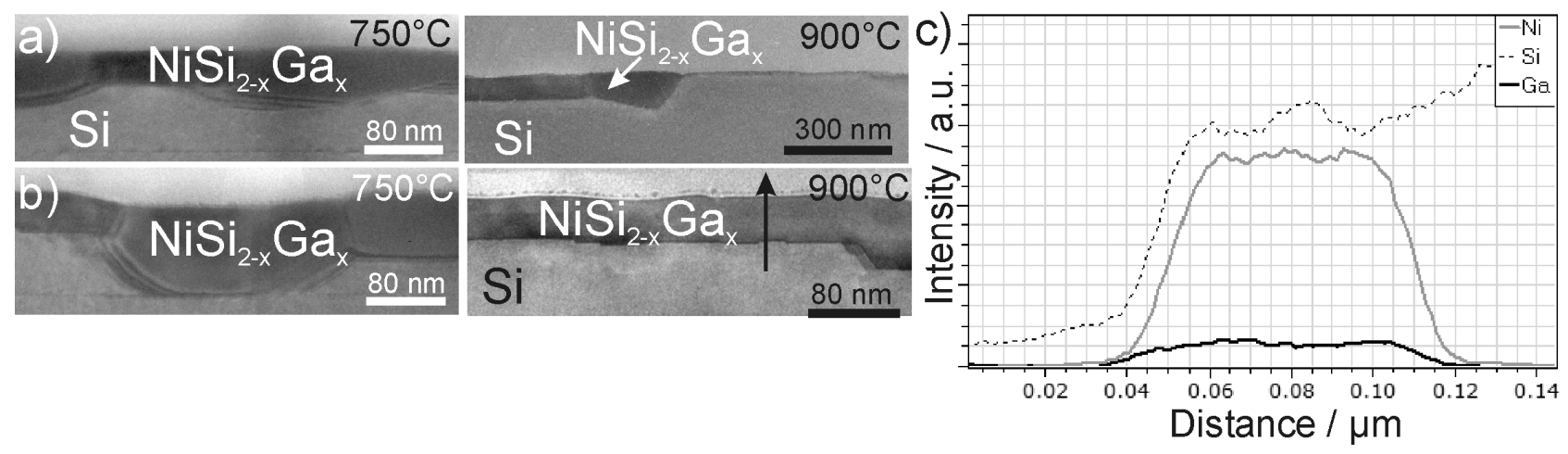

Figure 5: Cross-sectional TEM micrographs of samples with Ga contents a) $z=0.17$ and $b) z=0.28$ annealed at $750^{\circ} \mathrm{C}$ and $900^{\circ} \mathrm{C}$. c) EDXS line scan across the $\mathrm{NiSi}_{2-\mathrm{x}} \mathrm{Ga}_{\mathrm{x}}$ layer obtained at $\mathrm{z}=0.28$ and annealed at $900^{\circ} \mathrm{C}$ (see the black line in the corresponding cross-sectional image).

In contrast, at the higher $\mathrm{Ga}$ content of $\mathrm{z}=0.22 \ldots 0.28$ two different layer morphologies are present after annealing at $750^{\circ} \mathrm{C}$ : polycrystalline $\mathrm{NiSi}_{2-\mathrm{x}} \mathrm{Ga}_{\mathrm{x}}$ regions (Fig. 5b) and epitaxial A-type $\mathrm{NiSi}_{2-\mathrm{x}} \mathrm{Ga}_{\mathrm{x}}$ regions [20]. Higher annealing temperatures above $900^{\circ} \mathrm{C}$ lead to formation of epitaxial A-type $\mathrm{NiSi}_{2-\mathrm{x}} \mathrm{Ga}_{\mathrm{x}}$ layers only (Fig. 5b). EDXS analysis showed a homogeneous Ga distribution in the film (Fig. 5c). The layers exhibit preferentially the $\mathrm{NiSi}_{2-\mathrm{x}} \mathrm{Ga}_{\mathrm{x}}(001) / \mathrm{Si}(001)$ interface. However, the interfacial roughness varies locally up to $30 \mathrm{~nm}$ due to the presence of the $\mathrm{NiSi}_{2-\mathrm{x}} \mathrm{Ga}_{\mathrm{x}}\{111\}$ facets. Thus, further experiments are required to optimize the layer roughness.

\section{Summary}

Phase formation in the Ni-Al-Si and Ni-Ga-Si thin film system was investigated. Thin films of different atomic $\mathrm{Ni} / \mathrm{Al}$ and $\mathrm{Ni} / \mathrm{Ga}$ ratios were codeposited at room temperature onto $\mathrm{Si}(001)$ substrates by magnetron sputtering and molecular beam epitaxy, respectively. Subsequently, the layers were ex-situ annealed at different temperatures.

Addition of $\mathrm{Al}$ leads to a decrease of the disilicide formation temperature down to at least $500^{\circ} \mathrm{C}$. Without $\mathrm{Al}$ separated $\mathrm{NiSi}_{2}$ islands with the $\mathrm{A}$ - and $\mathrm{B}$-type orientations are observed at temperatures above $800^{\circ} \mathrm{C}$, whereas addition of $\mathrm{Al}$ leads to the formation of closed $\mathrm{NiSi}_{2-\mathrm{x}} \mathrm{Al}_{\mathrm{x}}$ layers. The layer roughness strongly depends on the $\mathrm{Al}$ content: almost smooth layers are observed at $\mathrm{Al}$ content $\mathrm{z}$ ranging from 0.2 to 0.3 . Under the presence of $\mathrm{Al}$ only A-type oriented $\mathrm{NiSi}_{2-\mathrm{x}} \mathrm{Al}_{\mathrm{x}}$ was observed.

Addition of $\mathrm{Ga}$ into the Ni-Si thin film system also results in a decrease of the disilicide nucleation temperature down to less than $450^{\circ} \mathrm{C}$ for the Ga content of $\mathrm{z}=0.22 \ldots 0.28$. In contrast to 
$\mathrm{Al}$, addition of $\mathrm{Ga}$ leads to a change in the disilicide $\mathrm{NiSi}_{2-\mathrm{x}} \mathrm{Ga}_{\mathrm{x}}$ orientation. Closed layers with a $\mathrm{NiSi}_{2-\mathrm{x}} \mathrm{Ga}_{\mathrm{x}}(110) \| \mathrm{Si}(001)$ texture are observed after a $750^{\circ} \mathrm{C}$ annealing at low Ga contents of $\mathrm{z}=$ $0.06 \ldots 0.17$. Similarly to the pure Ni-Si system island formation was observed after annealing above $900^{\circ} \mathrm{C}$ for these Ga concentrations. For higher Ga contents of $\mathrm{z}=0.22 \ldots 0.28$ closed A-type oriented $\mathrm{NiSi}_{2-\mathrm{x}} \mathrm{Ga}_{\mathrm{x}}$ layers were observed after the $900^{\circ} \mathrm{C}$ annealing. These layers exhibit preferentially the $\mathrm{NiSi}_{2-\mathrm{x}} \mathrm{Ga}_{\mathrm{x}}(001) / \mathrm{Si}(001)$ interface. However, there is still a large number of $\mathrm{NiSi}_{2-\mathrm{x}} \mathrm{Ga}_{\mathrm{x}}\{111\} / \mathrm{Si}\{111\}$ facets, which cause an interfacial roughness of about $30 \mathrm{~nm}$.

\section{References}

[1] L.J. Chen: Silicide Technology for Integrated Circuits (IEE, London 2004).

[2] C. Lavoie, F.M. d'Heurle, C. Detavernier, C. Cabral Jr.: Microelectronic Engineering Vol. 70 (2003), p. 144

[3] J.P. Sullivan, R.T. Tung, F. Schrey: J. Appl. Phys. Vol. 72 (1992), p. 478

[4] J.E.E. Baglin, H.A. Atwater, D. Gupta, F.M. D’Heurle: Thin Solid Films Vol. 93 (1982), p. 255

[5] M.Y. Lee, P.A. Bennett: Phys. Rev. Lett. Vol. 75 (1995), p. 4460

[6] K. Tsutsui, R. Xiang, K. Nagahiro, T. Shiozawa, P. Ahmet, Y. Okuno, M. Matsumoto, M. Kubota, K. Kakushima, H. Iwai: Microelectronic Engineering Vol. 85 (2008), p. 315

[7] D. Hesse, P. Werner, , R. Mattheis, J. Heydenreich: Mat. Res. Soc. Symp. Proc. Vol 320 (1994), p. 221

[8] K.C.R. Chui, J.M. Poate, J.E. Rowe, T.T. Sheng, A.G. Cullis: Appl. Phys. Lett. Vol. 38 (1981), p. 988

[9] V. Teodorescu, L. Nistor, H. Bender, A. Steegen, A. Lauwers, K. Maex, J.V. Landuyt: J. Appl. Phys. Vol. 90 (2001), p. 167

[10] K.L. Pey, P.S. Lee, D. Mangelinck: Thin Solid Films Vol. $462-463$ (2004), p. 137

[11]D. Deduytsche, C. Detavernier, R.L. Van Meirhaeghe, J.L. Jordan-Sweet, C. Lavoie: J. Appl. Phys. Vol. 101 (2007), p. 044508

[12]X.-P. Qu, Y.-L. Jiang, G.-P. Ru, F. Lu, B.-Z. Li, C. Detavernier, R.L. Van Meirhaeghe: Thin Solid Films Vol. 462-463 (2004), p.146

[13]C. Detavernier, X.P. Qu, R.L. Van Meirhaeghe, B.Z. Li, K. Maex: J. Mater. Res. Vol.18 (2003), p.1668

[14] J. Liu, D.L. Kwong: Appl. Phys. Lett. Vol. 88 (2006), p. 052109

[15]E.J. Jung, S.-W. Jung, H.-S. Kim, J.-H. Yun, S.H. Cheong, B.H. Kim, G.H. Choi, S.T. Kim, U.-I. Chung, J.T. Moon, B.I. Ryu: Microelectronic Engineering Vol. 82 (2005), p. 449

[16]K.W. Richter, K. Hiebl: Appl. Phys. Lett. Vol. 83 (2003), p. 497

[17] A. Katz, Y. Komem: J. Vac. Sci. Technol. A Vol. 7 (1989), p. 1484

[18] A. Katz, Y. Komem: Mat. Res. Soc. Symp. Proc. Vol. 100 (1988), p. 719

[19]F. Allenstein, L. Budzinski, D. Hirsch, A. Mogilatenko, G. Beddies, R. Grötzschel, H.-J. Hinneberg: Microelectronic Engineering Vol. 82 (2005), p. 474

[20]A. Mogilatenko, F. Allenstein, M.A. Schubert, M. Falke, G. Beddies, H.-J. Hinneberg, W. Neumann: Phys. Stat. Sol. (c) Vol. 5 (2008), p. 3752 